\title{
Gestão e transparência de dados educacionais na rede estadual paulista (1995-2018): a hegemonia gerencial
}

\author{
Management and transparency of educational data in the São Paulo state \\ network (1995-2018): managerial hegemony \\ Gestión y transparencia de los datos educativos en la red del estado de São \\ Paulo (1995-2018): hegemonía gerencial
}

EDUARDO DONIZETI GIROTTO

Orcid Id: http://orcid.org/0000-0002-9870-6188

Universidade de São Paulo

JOÃO VICTOR PAVESI DE OLIVEIRA

Orcid Id: https://orcid.org/0000-0002-2754-1611

Universidade de São Paulo

ISABEL FURLAN JORGE

Orcid Id: https://orcid.org/0000-0002-7548-3815

Universidade de São Paulo

\begin{abstract}
Resumo: $\mathrm{O}$ artigo analisa os sentidos das políticas de dados educacionais (abertos ou não), desenvolvidas pela Secretaria Estadual de Educação de São Paulo (SEDUC-SP) durante o período entre 1995 e 2018. Realizamos levantamento e análise documental exploratória, com enfoque qualitativo, das principais legislações que nortearam as políticas de gestão de dados educacionais na SEDUC-SP, articulando o modelo de gestão do Estado e relação com a sociedade civil. Os resultados apontam para uma política de dados vinculada, predominantemente, à racionalidade gerencial, à produção de resultados quantitativos, responsabilização e racionalização dos gastos em consonância com a centralidade que os princípios da Nova Gestão Pública assumiram nas políticas da SEDUC-SP no período analisado.
\end{abstract}

Palavras-chave: Dados Educacionais. Gerencialismo. Política Educacional.

\begin{abstract}
The article discusses the meaning of the educational data policies developed by the São Paulo State Department of Education (SEDUC-SP) between 1995 and 2018. We carried out a survey and exploratory documentary analysis, with a qualitative focus of the main legislation that guided the policies of educational data management at SEDUC-SP, articulating the State management model and relationship with civil society. The results point to a data policy linked, predominantly, to managerial rationality, the production of quantitative results, accountability, and rationalization of expenditures in line with the centrality that the principles of New Public Management assumed in the policies of SEDUC-SP in the analyzed period.
\end{abstract}

Keywords: Educational data. Managerialism. Educational politics. 
Resumen: El articulo analiza el significado de las politicas de datos educativos desarrolladas por el Departamento de Educación del Estado de São Paulo (SEDUC-SP) entre 1995 y 2018. Realizamos una encuesta y análisis documental exploratorio, con un enfoque cualitativo sobre la legislación principal que guio las politicas de gestión de datos educativos en SEDUCSP, articulando el modelo de gestión del Estado y relación con la sociedad civil. Los resultados apuntan a una politica de datos vinculada, predominantemente, a la racionalidad administrativa, la producción de resultados cuantitativos, la rendición de cuentas y la racionalización de los gastos en línea con la centralidad que los principios de la Nueva Gestión Pública asumieron en las políticas de SEDUC-SP en el período analizado.

Palabras clave: Datos educativos. Gerencialismo. Politica educativa.

\section{INTRODUÇÃO}

A busca pela fiscalização da ação do Estado tem sido uma das marcas dos discursos acerca das possibilidades de democratização da sociedade capitalista, com especial ênfase a partir da segunda metade do século XX. Diferentes são as leituras e interpretações de como deve ocorrer tal fiscalização, bem como o papel dos diferentes sujeitos sociais neste processo (BOBBIO,1986; ISSA, 2013). De um lado, é possível identificar posições mais progressistas que apontam a importância desta fiscalização como um dos movimentos necessários ao processo de ampliação da participação de diferentes grupos da sociedade civil organizada, com ênfase na participação política, na tomada de decisões, na disputa dos sentidos das políticas públicas e na consolidação da democracia. De outro lado, temos a defesa da fiscalização como um momento de constituição da modernização do Estado, na busca por maior eficiência e eficácia do gasto público, em consonância com as reformas gerencialistas, propostas em diálogo com os pressupostos neoliberais de gestão do Estado no capitalismo. Neste segundo conjunto de posições, destacam-se os defensores da Nova Gestão Pública (NGP). Em ambos os casos, há um elemento em disputa, sem o qual pouco é possível avançar em termos de fiscalização da ação do Estado. Trata-se da produção e do acesso aos dados governamentais, aqui concebidos como o conjunto de informações recolhidas, produzidas e sistematizadas pelos diferentes órgãos da gestão pública.

A revolução tecnológica da década de 1970, com o advento da computação, ampliou a capacidade da produção, armazenamento e organização de dados governamentais. Desde então, este processo tem se complexificado com o aparecimento de outros sujeitos a romperem com o monopólio do Estado na estruturação e compilação dos dados. Se até os anos 1970 os dados eram uma questão de soberania nacional e, portanto, diretamente vinculados aos interesses do Estado Nacional, hoje há um conjunto de agentes transnacionais com capacidade de armazenar, sistematizar e difundir dados que, inclusive, podem vir a colocar a soberania nacional em risco. 
Dessa forma, o principal objetivo deste texto é analisar os sentidos das políticas de dados educacionais (abertos ou não), desenvolvidas pela Secretaria Estadual de Educação de São Paulo (SEDUC-SP) durante o período entre 1995 e 2018. Na perspectiva teórico-conceitual assumida nesta pesquisa, analisar os sentidos se assenta no reconhecimento da política pública como um campo de disputa, mediada por intencionalidades, processos e sujeitos em diferentes escalas socioespaciais. Trata-se de compreender que os processos de elaboração, implementação e avaliação de políticas públicas estão mediados, constantemente, por interesses e estratégias de diferentes ordens, sendo necessário construir análises que articulem estas dimensões não explícitas na expressão formal da política. Como aponta Souza (2006),

As políticas públicas repercutem na economia e nas sociedades, daí por que qualquer teoria da política pública precisa também explicar as inter-relações entre Estado, política, economia e sociedade. Tal é também a razão pela qual pesquisadores de tantas disciplinas - economia, ciência política, sociologia, antropologia, geografia, planejamento, gestão e ciências sociais aplicadas partilham um interesse comum na área e têm contribuído para avanços teóricos e empíricos (p. 25)

Desse modo, partimos da hipótese de que não é possível entender os rumos das políticas de transparência de dados ${ }^{1}$ e do governo aberto na atualidade sem o entendimento da hegemonia que a Nova Gestão Pública (NGP) tem consolidado nesse processo. Se é fato que as políticas de transparência de dados e governos abertos são anteriores ao aparecimento da NGP como demonstraremos a seguir, tal lógica de gestão da máquina pública no capitalismo só pode se consolidar se puder desenvolver uma concepção de gestão de dados. Os princípios que baseiam a NGP (VERGER \& NORMAND, 2015) estão diretamente vinculados a mecanismos de produção de resultados e de responsabilização (accountability) que não podem ser realizados sem o acesso e a manipulação de informações em maior nível de desagregação, como demonstrado em pesquisas anteriores (GIROT'TO, 2016; GIROTTO et al, 2017). No caso da NGP, a política de dados vem sendo

\footnotetext{
Na perspectiva teórico-conceitual assumida nesta pesquisa, a transparência refere-se à disponibilidade pública de informações abrangentes, relevantes e confiáveis sobre as atividades do governo, disponibilizadas de forma oportuna, com qualidade, sendo essencial para fornecer uma base contínua para a aprovação dos governantes pelos cidadãos; e abrange a divulgação rotineira dos orçamentos, auditorias, políticas e ações executivas, servindo como fonte de informação para avaliar a eficácia da ação administrativa, por parte dos cidadãos, ampliando as exigências sobre os serviços públicos que são prestados pelo governo (DE FERRANTI et al., 2009 apud KLEIN; KLEIN \& LUCIANO, 2019). Nesse sentido, a transparência pode resultar no incremento considerável do controle social pelo cidadão, pois "a transparência, para ser funcional à sociedade democrática e aos cidadãos, precisa conseguir monitorar as iniciativas do governo. Nessa perspectiva, ampliar a transparência do DAG [dado aberto governamental] pode equivaler a ampliar o controle social pelo cidadão" (KLEIN; KLEIN \& LUCIANO, 2019, p. 10).
} 
posta a serviço da eficiência e eficácia da máquina estatal, tendo como referência as lógicas administrativas presentes no setor privado. Trata-se, assim, de ações que se localizam muito mais no campo da economia, da gestão e da administração, do que no campo da política e da participação popular.

Para a análise aqui proposta, realizamos um levantamento das principais legislações que nortearam as políticas de gestão de dados educacionais no estado de São Paulo e sua articulação com as políticas nacionais e internacionais, construindo possíveis interpretações dos sentidos que elas assumiram no interior da lógica de gestão do Estado e da relação com a sociedade civil organizada. Trata-se de uma primeira etapa, baseada em análise documental, com enfoque qualitativo, de pesquisa desenvolvida com financiamento da FAPESP ${ }^{2}$ e que tem como intuito compreender a gestão da política educacional na rede estadual de São Paulo entre os anos de 1995 e 2018.

$O$ texto encontra-se estruturado em três partes: na primeira, a partir da discussão sobre relação entre democracia e visibilidade das ações do Estado, fazemos um breve histórico das políticas de dados abertos no mundo e no Brasil como subsídio para a análise - desenvolvida na segunda e na terceira partes do texto - das possíveis relações e tensionamentos com os princípios da Nova Gestão Pública e seus impactos sobre a qualidade dos dados educacionais disponibilizados no país e, mais especificamente, na rede estadual de São Paulo, a partir da análise das principais legislações acerca da gestão de dados educacionais nesse estado e das suas possíveis intencionalidades. Por fim, discutimos os resultados da política hegemônica de gestão de dados educacionais no estado de São Paulo, principalmente com o intuito de compreender, se ao longo do período analisado, configurou-se maior ou menor abertura para o diálogo com a sociedade civil organizada.

\section{DEMOCRACIA, TRANSPARÊNCIAS E DADOS GOVERNAMENTAIS ABERTOS: BREVES CONSIDERAÇÕES}

Bobbio (1986) define a democracia como o governo do poder público em público. Ao analisar diferentes concepções e debates acerca da democracia ao longo da história, o autor chama atenção sobre o tema do poder visível. Em certa medida, para os defensores da democracia, este seria o principal avanço em relação aos modelos anteriores de organização política. Segundo o autor,

2 Processo no 2018/09983-0. Cf. https://www.repu.com.br/pesquisa-fapesp. 
"no Estado autocrático, o segredo de Estado não é a exceção, mas a regra: as grandes decisões políticas devem ser tomadas ao abrigo dos olhares indiscretos de qualquer tipo de público" (BOBBIO, 1986, p. 94).

A tentativa de tornar cada vez mais visível a ação do Estado para todos os cidadãos pode ser lida como um dos objetivos dos defensores das políticas de transparência de dados e governos abertos no interior das democracias modernas. Desde a Declaração Universal dos Direitos Humanos (1948)³ , o acesso à informação é considerado um direito humano fundamental. Mesmo já existindo países em que normas de acesso à informação fossem anteriores à Declaração Universal $^{4}$, foi com a promulgação da Lei de Liberdade de Informação (Free of Information Act - FOLA) de 1966, nos Estados Unidos, que se iniciou uma rápida multiplicação de normativas entre os países, concretizando tal direito. No Brasil, a Constituição Federal de 1988, alinhada ao documento universal, apresenta, no artigo $5^{\circ}$, inciso XXXIII, a garantia do acesso à informação pública dentre o conjunto dos direitos e garantias fundamentais. Com a popularização da Internet nos anos 90, a rede de computadores se torna um instrumento que permite a disponibilização, o acesso e a compilação de grande quantidade de informações, dando força para que se efetivassem as políticas de dados abertos.

No caso brasileiro, será somente em $2011^{5}$ que entrará em vigor a primeira Lei de Acesso à Informação (n $12.527 / 2011)^{6}$, regulamentada no ano seguinte pelo decreto $\mathrm{n}^{\mathrm{o}} 7.845 / 2012$. Essas normativas jurídicas garantem a todo cidadão brasileiro o direito de acesso à informação produzida ou armazenada por órgãos ou entidades da União, Estados, Distrito Federal e Municípios. Baseada na ideia de tornar público, para uso da sociedade, os dados mantidos pelo Estado, a

3

“Todos os homens têm direito à liberdade de opinião e expressão; este direito inclui a liberdade de, sem interferências, ter opiniões e de procurar, receber e transmitir informações e ideias por quaisquer meios e independentemente de fronteiras."

4 A primeira norma desse tipo surge em 1766, na Suécia. A segunda, data de 1951, na Finlândia. E a terceira é a lei promulgada nos Estados Unidos, em 1966 (ANGÉLICO, 2012 apud ISSA, 2013).

5 O paradigma dos dados abertos governamentais ganhou espaço na agenda da gestão pública brasileira, especialmente a partir do protagonismo desempenhado pelo país na Open Government Partnership, em 2011, ocasião em que o Brasil, ao lado de outros sete países, assumiu compromissos nos campos da participação, da colaboração, do combate à corrupção e da transparência, contando para tanto com o suporte das novas Tecnologias de Informação e Comunicação (TIC) (POSSAMAI \& SOUZA, 2020).

6 Sob inspiração da participação brasileira na Open Government Partnership, a Lei de Acesso à Informação (LAI) tornou-se a primeira norma de acesso à informação no mundo a incorporar à dimensão da transparência o paradigma dos dados abertos. Além disso, em 2012, foi criado o Portal Brasileiro de Dados Abertos (http:// dados.gov.br/). Porém, como destacam as análises de Possamai e Souza (2020), apesar dos avanços registrados com a incorporação de princípios dos dados abertos governamentais na Lei de Acesso à Informação, a adoção do paradigma no Brasil é desafiada pela amplitude das hipóteses de negativas de acesso, de ordem substancial e processual. 
lei brasileira está fundamentada nos princípios dos dados abertos ${ }^{7}$, que buscam reforçar a transparência dos governos "através do aumento da participação social, a melhoria do bem-estar público e uma utilização mais eficiente dos recursos públicos" (OPENGOVDATA, 2007).

Em síntese, ao liberar publicamente dados em formatos não proprietários e sem licenças restritivas o governo permitiria a um conjunto de atores se apropriar das informações e gerar análises, produtos e serviços que retornariam na forma de benefícios para a própria sociedade (...). (SANTOS, 2014, p. 14)

É importante destacar que nem todas das informações disponibilizadas pelos órgãos públicos são, necessariamente, consideradas dados abertos. Segundo Issa (2013),

Publicar em formato aberto significa disponibilizar online bases de dados de modo que esses conteúdos possam ser reestruturados, reprocessados e relacionados a outros dados e a outras bases de dados. Disponíveis em formato de dados abertos, bases de dados podem ser cruzadas com outras bases que também estejam publicadas nesse formato e, assim gerar diversas variáveis que podem ser úteis tanto para investigações específicas de indivíduos e entidades da sociedade civil, quanto para a pesquisa teórico-acadêmica ou mesmo para o desenvolvimento de inovações em produtos e serviços ou, ainda, para o aprimoramento de procedimentos de gestão de estruturas e processos públicos e privados. Só podem ser considerados abertos os dados que possam ser reutilizados ou reaplicados a outras finalidades. Significa dizer que somente são tidos como abertos os dados que estejam livres de qualquer obstáculo técnico a que possam ser automaticamente relacionados com outros dados quaisquer (ISSA, 2013, p. 16)

Destaca-se, nessa definição de dados abertos, a importância do uso livre da informação e a correlação com outras variáveis, inclusive, resultando na produção de novos dados e informações. Segundo os defensores dos princípios do governo aberto, essa disponibilização pública dos dados, sua apropriação e reconstrução oferece à sociedade maior participação e controle social da gestão pública, permitindo reduzir a assimetria de informações entre o governo e a sociedade civil na direção de tornar públicas e visíveis as ações do governo, nos termos discutidos por Bobbio (1986). Com isso, seria possível que entidades da sociedade civil fiscalizassem a aplicação dos recursos públicos, avaliando os resultados das políticas públicas, participando do controle e fiscalização dos governos. Além disso, os cidadãos teriam a sua disposição ferramentas de transparência que lhes permitiriam analisar a qualidade dos serviços públicos, orientando suas escolhas. Os defensores dos dados abertos veem nessa política de transparência uma forma 
do governo aumentar os canais de comunicação com a sociedade, reforçando as práticas democráticas, a eficiência dos serviços públicos e o desenvolvimento econômico (SANTOS, 2014). Por outro lado, alguns críticos alertam que esse processo de disponibilização de dados não é suficiente para que um governo se estabeleça como verdadeiramente aberto e democrático quanto à equidade no acesso e uso da informação, já que, em uma sociedade desigual, aqueles que possuem maiores recursos para tirar proveito do acesso a esses dados serão privilegiados (SANTOS, 2014) e conseguirão de fato utilizá-los, enquanto a maior parte da sociedade continuará não tendo acesso a esses recursos, permanecendo afastada da possibilidade de fiscalizar a aplicação dos recursos públicos e avaliar os resultados das políticas públicas e mesmo de se utilizar desses dados para orientar suas ações em relação aos serviços públicos.

Já em Bobbio encontramos algumas problematizações acerca dessa questão. Segundo o autor, uma das questões de base a ser discutida diz respeito à capacidade da democracia de debelar o poder invisível, uma das marcas das organizações políticas pré-democráticas. Para Bobbio, a resposta para essa questão é negativa, considerando o avanço de novos poderes invisíveis nas democracias modernas, como visto nas ações dos grandes grupos econômicos na condução da política, ao qual o autor denominou de governo da economia.

À diferença do poder legislativo e do poder executivo tradicional, o governo da economia pertence, em grande parte, à esfera do poder invisível, na medida em que se subtrai (se não formalmente, ao menos substancialmente) ao controle democrático e ao controle jurisdicional (BOBBIO, 1986, p. 103)

No entanto, o mais preocupante, segundo o autor, no que se refere à manutenção do poder invisível nas democracias modernas, diz respeito à capacidade - pelo avanço das telecomunicações e da informática - de uma inversão do jogo: ao invés de ser fiscalizado, o Estado criaria mecanismos cada vez mais sofisticados de vigiar os seus cidadãos, em uma complexificação do panóptico de Bentham.

\footnotetext{
Se esta perspectiva é apenas um pesadelo ou um destino ninguém está em condições de prever. Seria de todo modo uma tendência oposta à que deu vida ao ideal da democracia como ideal do poder visível: a tendência não mais rumo ao máximo controle do poder por parte dos cidadão, mas ao contrário rumo ao máximo de controle dos súditos por parte de quem detém o poder (BOBBIO, 1986, p 106)
}

Esta inversão do jogo não seria um dos princípios da política de dados sob a hegemonia da NGP na rede estadual de educação de São Paulo? O controle centralizado das informações e a diminuta preocupação em ampliar o acesso aos 
dados e a discussão pública destes não tem sido a tônica das ações realizadas pela SEDUC-SP? Nas próximas seções deste texto, à luz das questões trazidas pelos autores, aprofundaremos a análise acerca dos dados educacionais abertos no Brasil e no estado de São Paulo.

\section{OS DADOS EDUCACIONAIS ABERTOS NO BRASIL}

A obtenção de informações sobre a realidade educacional brasileira tem início com a criação do Ministério da Educação e Saúde, em 1931 (LIMA \& SOUSA, 2014). Mesmo já tendo ocorrido levantamento de informações sobre a instrução da população, no primeiro censo demográfico feito no país, em 1872, é nesse momento que se firma uma rotina de sondagens educacionais, situada no processo da centralização administrativa do Estado brasileiro, logo após a Revolução de 1930, que alçou Getúlio Vargas à presidência do país, desencadeando um processo de modernização, baseado em projeto nacional desenvolvimentista. Foi neste contexto que se deu a criação de diferentes órgãos de coleta, produção e sistematização de dados sobre o território nacional, fundamental para a centralização administrativa do país proposta por Vargas.

No caso dos dados educacionais, o primeiro movimento de coleta, produção e sistematização se deu através da parceria do Ministério com a Associação Brasileira de Educação $(\mathrm{ABE})^{8}$, por meio da assinatura do Convênio Estatístico em 1931, que determinava que os trabalhos oficiais de estatística educacionais fossem públicos e disseminados com rapidez e segurança. A produção uniformizada desses dados prometia confeccionar um levantamento anual minucioso dos aspectos administrativo, financeiro, espacial, material, docente, discente e didático, envolvidos na educação brasileira, permitindo delinear as condições gerais dos diversos níveis de ensino do país e, em particular, de cada Estado, do Distrito Federal e do Território do Acre, em determinado ano. Com esta finalidade foi criado, por meio da lei no 378 de 1937, o Serviço de Estatística da Educação e Saúde, alterado em 1956, pelo Decreto n 38.661, para Serviço de Estatística da Educação e Cultura (SEEC). Em 1939 publica-se "O ensino no Brasil no quinquênio 1932-1936", correspondendo ao primeiro documento com estatísticas da educação nacional.

8 Criada em 1924, a ABE cumprirá um importante papel nas mudanças que o sistema educacional brasileiro sofrerá na segunda metade dos anos 20 e na década seguinte. É a partir dela que a sociedade civil passa a participar dos debates sobre políticas educacionais, até então restritas ao interior do Estado, formulando sugestões como na elaboração do Manifesto dos pioneiros da educação nova (1932). 
De acordo com Lima e Souza (2014), com o golpe Civil-Militar de 1964, os levantamentos das informações educacionais passam a ser realizados pelo Escritório de Pesquisa Econômica Aplicada (EPEA) ${ }^{9}$, que tinha a função de consolidar os dados e análises ${ }^{10}$, com o objetivo de elaborar diagnósticos da educação brasileira para o Plano Decenal. Seguindo os preceitos autoritários do regime, em 1971 foi aprovada, com pouca negociação no Congresso, a Lei de Diretrizes e Bases da Educação Nacional (nº 5.692/71) que determinava:

Art. 20 - O Ensino de $1^{\circ}$ Grau será obrigatório no período etário dos 7 aos 14 anos, cabendo aos municípios promover, anualmente, o levantamento da população que alcance a idade escolar e proceder à sua chamada para matrícula. (grifo nosso)

É na década de 1980 que o Censo Escolar passa a ser realizado pelo Serviço de Estatística da Educação e Cultura (SEEC), tendo sua sede transferida para Brasília e estando subordinado à Secretaria de Informática (Seinf/MEC). Durante os anos 1990, o SEEC correu o risco de ter suas atividades suspensas devido à perda hierárquica que sofreu na estrutura organizacional do Ministério da Educação (MEC). Entretanto, manteve as metas estabelecidas e procedeu com a descentralização da coleta dos dados do Censo Escolar por meio de um sistema informatizado. Em 1996, o SEEC é incorporado à Secretaria de Avaliação e Informação Educacional (SEDIAE/MEC), e, em 1997, a SEDIAE é absorvida pelo Instituto Nacional de Estudos e Pesquisas Educacionais Anísio Teixeira (INEP), que passa a ser o órgão oficial, na esfera federal, encarregado pelos levantamentos estatísticos educacionais.

Atualmente, o Censo Escolar da Educação Básica vem sendo realizado anualmente pelo MEC/INEP/DEED ${ }^{11}$ em parceria com as Secretarias de Educação estaduais e municipais, que são as responsáveis pelo levantamento de informações estatístico-educacionais sobre a educação básica brasileira. O informante do Censo Escolar é o diretor da unidade escolar ou pessoa responsável indicada. Nessa pesquisa, são coletados dados educacionais, tanto sobre a infraestrutura da escola, como sobre o pessoal docente, matrículas, jornada escolar, rendimento e movimento escolar, por etapa e modalidade de ensino, dentre outros ${ }^{12}$.

O EPEA foi criado em 1964, tendo seu nome alterado após três anos para Instituo de Pesquisa Econômica Aplicada (IPEA). Sob a supervisão de Mário Henrique Simonsen, o Instituto foi estabelecido para realizar estudos, pesquisas e análises nas esferas econômica e social solicitadas pelo Ministério do Planejamento.

10 Posteriormente, a partir de 1996, esse levantamento de informações educacionais realizado anualmente passou a ser denominado Censo Escolar.

11 DEED - Diretoria de Estatísticas Educacionais

12 Disponível em: <https://ces.ibge.gov.br/apresentacao/portarias/200-comite-de-estatisticassociais/base-de-dados/1185-censo-escolar-educacao-basica.html>. Acessado em 25 de nov. 2019. 
Com informações das redes de ensino federal, estadual e municipal, de escolas públicas e privadas, o Censo oferece uma importante base de informações sobre a Educação Básica no Brasil, permitindo a elaboração de diagnósticos acerca do ensino e disponibilizando um conjunto de dados que podem subsidiar o planejamento, a execução e o acompanhamento das políticas públicas. Permite, também, análises acerca de determinados elementos da realidade educacional brasileira em série histórica, ainda que se considere todas as mudanças metodológicas ocorridas com o Censo Escolar ao longo dos anos, discussão que foge ao escopo deste texto.

Uma exemplificação da relevância das informações oferecidas pelo Censo Escolar está no FUNDEB ${ }^{13}$, que corresponde a um fundo de redistribuição de recursos financeiros para a Educação Básica aos estados da federação que necessitam de complementação financeira para atingir um valor mínimo, definido nacionalmente, de repasses por aluno. Os dados de alunos matriculados nas redes estaduais, sistematizados pelo Censo, servem de referência para tal complementação.

No entanto, todas as informações coletadas e compiladas pelo MEC/ INEP/DEED, relevantes para avaliação e acompanhamento das políticas educacionais, não estão facilmente acessíveis pela sociedade geral. Pelo contrário, o que verificamos, até aqui, foi a predominância de determinados grupos, diretamente vinculados a setores privados (Todos pela Educação, Fundação Lemann, Instituto Ayrton Senna, Instituto Unibanco), na apropriação e disseminação dos dados educacionais, construindo plataformas virtuais, acessíveis e descomplicadas ao público em geral ${ }^{14}$. Ao mesmo tempo, vemos emergir um conjunto de empresas, no campo da mineração dos dados educacionais, que passaram a compreender a importância estratégica deste setor para o avanço de processos de privatização das diferentes etapas da educação pública no Brasil. Assim, reconhece-se um caráter contraditório das políticas de dados abertos, tal como ela vem se configurando no contexto educacional brasileiro, pois, ao invés de se traduzir em um instrumento

13 Fundo de Manutenção e Desenvolvimento da Educação Básica e de Valorização dos Profissionais da Educação.

14 Como a plataforma do Observatório do PNE (https://www.observatoriodopne.org.br/home), desenvolvida pelo Todos pela Educação, que tem como objetivo oferecer indicadores para o monitoramento das 20 metas e 254 estratégias do Plano Nacional de Educação; e o site da QEdu, uma startup da Fundação Lemann, que tem o objetivo de "dar vida aos dados educacionais para auxiliar gestores, diretores, professores e todos os interessados a fazerem melhores escolhas na educação", aplicando "tecnologias inovadoras e design moderno para facilitar o acesso aos dados educacionais" (https://www.qedu.org.br/sobre), disponibilizando para "cada escola, cidade, estado e para o Brasil, (...) acesso fácil, rápido e intuitivo a diversos dados educacionais, como a Prova Brasil, o Censo Escolar, Ideb e Enem. Todos obtidos de fontes oficiais do governo para ajudar você a transformar a educação brasileira" (https://www.qedu.org.br/sobre/dados-disponiveis). 
que impulsione o controle da sociedade sobre a administração pública, acaba beneficiando interesses privados e fortalecendo os mecanismos de controle da NGP.

Éimportante ressaltarque a centralidade da NGP nas políticas educacionais é resultado do contexto de recessão econômica dos anos 1980 no Brasil e em diferentes países da América Latina. Tal situação pressionou os governantes a adotarem a cartilha de racionalização dos recursos públicos, impulsionada pelos organismos multilaterais como Banco Mundial e Fundo Monetários Internacional (FMI). Simultaneamente a isso, a ampliação da escolarização definida pela Constituição Federal de 1988 e reafirmada pelos acordos assinados pelo governo brasileiro durante a Conferência Mundial sobre Educação para Todos, em 1990, em Jomtien, na Tailândia, trouxe o discurso da necessidade de um acompanhamento da aprendizagem dos alunos a fim de verificar se o dinheiro público vinha sendo gasto de maneira adequada. Pode-se indicar que é nesse contexto que as avaliações externas são aperfeiçoadas e ganham maior destaque nas políticas educacionais. Fletcher (1995), estudioso das avaliações em larga escala e contribuidor para o desenvolvimento do Sistema Nacional de Avaliação da Educação Básica (Saeb), defendia uma avaliação de todo sistema educacional que estabelecesse uma base de informações contínuas, de longo prazo e censitárias, levando em consideração as condições internas das escolas; assim, se definiriam padrões que pudessem comparar o desempenho da qualidade de ensino entre as unidades escolares, monitorando as políticas educacionais.

De fato, isto caracteriza a situação do ensino brasileiro nos dias de hoje [1995], onde a falta de qualquer tentativa de avaliação externa obscurece as verdadeiras dimensões das dificuldades educacionais e contribui para a erosão da qualidade do ensino público. Sem uma visão clara das necessidades, é extremamente difícil angariar recursos para o setor e contribuir para a solução dos eventuais problemas. Uma das vantagens da avaliação extrínseca seria, portanto, seu potencial de produzir resultados comparativos e identificar prioridades. (FLETCHER, 1995, p. 107)

Mesmo sem mencionar literalmente, Fletcher traz para o debate a ideia de accountability, na ambiguidade própria que há no termo. Para ele, as avaliações externas tendem a oferecer um conjunto de dados que, associados a outras informações, revelariam diagnósticos sobre ensino-aprendizagem, dando transparência aos gastos públicos e responsabilizando os sujeitos que não são eficientes tanto no âmbito pedagógico (professores cujos alunos não atingem as metas estipuladas, por exemplo), quanto no da gestão de recursos. 
Diferentemente do que Fletcher sugeriu, não ocorreu a construção desses bancos de dados censitários a partir das provas padronizadas, que permaneceram amostrais e sem uma periodicidade anual. As avaliações externas padronizadas ganharam, no entanto, centralidade na construção dos diagnósticos e principalmente na elaboração das políticas públicas (BROOKE \& CUNHA, 2011). A criação, em 2007, do Índice de Desenvolvimento da Educação Básica (Ideb) coroará esse movimento, resultando em uma significativa mudança na estruturação e na qualidade das informações dispostas no Censo Escolar, a partir de então. Essas alterações vêm no sentido de permitir que, agentes públicos e sociedade civil, possam esmiuçar as características internas das escolas a partir dos resultados obtidos no Ideb. Com isso, as informações estatístico-educacionais que inicialmente serviam preferencialmente para diagnosticar as condições da escola pública, assumem agora também o papel de indutoras das mudanças nas políticas públicas. Núñez, Kolinski e Fernández (2019) apresentam uma revisão sobre a política de uso de dados educacionais (internacionalmente conhecido por data use policies), oferecendo um plano de fundo para este processo. Comparando o Brasil e os Estados Unidos no uso de dados em programas educacionais, as autoras identificaram que, devido à longa disseminação de avaliações externas neste último, há um maior apoio em dados para elaboração de programas educacionais, sobretudo a partir a política No Child Left Behind. No caso brasileiro, o uso das informações das avaliações externas tem tido foco somente nas políticas de responsabilização; em que a ação predomina na divulgação dos resultados em relatórios e boletins pedagógicos às escolas, sem surtir efeitos no processo de aprendizagem. As autoras concluem que, no contexto do Brasil, a utilização dos dados educacionais está restrita às políticas de responsabilização escolar a partir da proliferação de avaliações externas entre os sistemas estaduais de ensino, mesmo com estudos demonstrando que seus impactos não são nítidos e duradouros.

Nesse sentido, diferentes autores têm feito críticas aos usos dos resultados do Ideb (CALDERANO, 2013; FREITAS, 2007). O principal teor da crítica consiste na descontextualização dos resultados, reforçando aquilo que Azanha (2014) denominou de abstracionismo pedagógico. Essa descontextualização possibilita aos gestores da política produzir comparações sobre fenômenos e processos qualitativamente diferentes. Tais comparações, por sua vez, têm sido utilizadas na construção de políticas de carreira docente, de reorganização escolar, entre outras. Poucos têm sido os exemplos em que os dados dos Ideb foram utilizados para ampliar a participação da comunidade escolar nos debates acerca da qualidade educacional. Na maioria dos casos, nem mesmos os docentes e discentes têm acesso aos dados, o que contribui para fortalecer a intencionalidade de controle e responsabilização implícita na política. 
Assim, é possível perceber que esta tipologia revela uma intencionalidade no uso e divulgação dos dados. A maior facilidade de apropriação dos indicadores de performance, como o Ideb, os resultados do Exame Nacional do Ensino Médio (Enem), o Índice de Desenvolvimento da Educação do Estado de São Paulo (Idesp), busca favorecer a lógica do quase mercado na educação, em detrimento de análises mais complexas, de contexto, que precisam da correlação de dados (orçamentários, demográficos).

Grande parte dos países têm utilizado indicadores baseados na proficiência dos alunos em avaliações cujo resultado refletiria a qualidade de ensino de uma escola. No caso de políticas de mercado onde as escolas competem entre si e o financiamento público é proporcional ao número de matrículas efetuadas, a transparência dos indicadores faz parte das regras de funcionamento deste mercado gerando incentivos sistêmicos para expandir as melhores escolas e eliminar as de pior desempenho (SANTOS, 2014, p. 26).

É importante ressaltar que esta monopolização das políticas de dados e governo aberto pela NGP já têm um lastro histórico nas políticas educacionais inglesas postas em prática a partir da década de 1980. Segundo Santos (2014), a política de abertura dos dados educacionais na Inglaterra está vinculada às políticas de quase mercado estabelecidas no país a partir de 1988 que levaram ao aumento da competição entre as unidades escolares, com o fechamento de escolas consideradas ruins. De forma geral, no caso inglês, o modelo hegemônico de política pública de abertura dos dados educacionais tem servido para que os pais possam decidir onde irão matricular seus filhos. Segundo o autor,

\begin{abstract}
No início da disponibilização pública dos dados dos indicadores de performance escolar já havia a preocupação com o efeito negativo da transparência, mais especificamente na possibilidade de comparação direta entre escolas sem levar em conta o seu contexto: as piores escolas do ranking eram em geral as que estavam próximas às áreas mais pobres da cidade o que caracterizava uma segregação territorial e criava uma dificuldade extra em reter profissionais qualificados em função da imagem negativa daquela escola - surgia o efeito de "nomear e se envergonhar" ou do inglês "naming and shaming" (SANTOS, 2014, p.21)
\end{abstract}

Trata-se, nestes termos, de uma lógica de política de dados abertos focados na comparação de performance individual de alunos e unidades escolares, o que pode ser destacado como um dos mecanismos de difusão do quase mercado nas políticas educacionais inglesas, nas últimas décadas. Para isso, os dados são divulgados em plataformas de fácil acesso para a maior parte da população, permitindo, assim, o uso das informações para a tomada de decisões. $\mathrm{Na}$ direção oposta, os dados que exigem maior complexidade de compreensão, principalmente 
os que tratam dos contextos da educação e suas implicações nos processos de ensino-aprendizagem e no próprio entendimento das desigualdades educacionais e suas articulações com outras variáveis (renda, distribuição de equipamentos públicos e privados, desigualdades de gênero, raça, etc.), tiveram poucos avanços no que diz respeito à transparência e à apropriação pela população.

A análise do caso inglês aponta para importância de se compreender a indissociabilidade entre as políticas de dados abertos e os objetivos das políticas educacionais. Como dissemos, também as políticas de dados abertos precisam ser lidas no interior dos conflitos que envolvem as disputas pelos sentidos e lógicas das políticas educacionais. É fundamental localizar tais conflitos e contradições no interior da consolidação da NGP como lógica hegemônica de política educacional, fugindo, portanto, de interpretações ingênuas e reconhecendo os interesses amplamente econômicos no que se refere ao acesso a informações desagregadas no nível dos indivíduos e com rápida atualização, como apontado por Santos (2014), em referência ao caso inglês.

Um exemplo que evidencia como as políticas de dados abertos, no contexto descrito anteriormente, vem favorecendo a apropriação privada das informações educacionais, é apresentado no trabalho de Baker, Isotani e Carvalho (2011), no qual os autores enumeram as diversas possibilidades trazidas pela mineração de dados à realidade educacional brasileira.

Trata-se, por exemplo, da construção de modelos de predição que possibilitem entender quais são os processos de ensino-aprendizagem mais eficazes para cada uma das etapas da educação básica. Para que a mineração de dados possa avançar, os autores defendem a necessidade de se ampliar o acesso aos bancos de dados educacionais, produzidos pelos diferentes níveis de governo, inclusive aqueles que estão desagregados por indivíduo. Para os autores,

Com a difusão destes repositórios de dados educacionais abertos diminuise a necessidade de (a) recrutar escolas, professores, e estudantes; (b) realizar estudos convencionais que requerem recursos humanos especializados; (c) ir para escolas e conduzir experimentos que duram dias ou até semanas; (d) inserir, formatar e digitalizar os dados obtidos; e etc. Essa abordagem poderá salvar grande parte do tempo e dos custos envolvidos em pesquisas educacionais. Além disso, os resultados poderão ser obtidos mais rapidamente, serão mais precisos e, finalmente, proporcionarão o desenvolvimento de práticas pedagógicas que podem ser utilizados para melhorar a qualidade do ensino de forma eficaz (BAKER, ISOTANI, CARVALHO, 2011, p. 8)

É importante notar a ênfase que os autores dão à diminuição dos custos das pesquisas educacionais como resultado da diminuição da necessidade de realizar visitas às unidades escolares, para o desenvolvimento de observações, 
entrevistas, procedimentos próprios dos estudos qualitativos em educação. Há, nessa concepção, o reforço de que os dados obtidos por meio dos grandes bancos informatizados seriam suficientes para compreender a complexidade dos processos educativos. Inclusive, o acesso aos dados, sua sistematização e análise também seriam fatores suficientes para a elaboração de modelos preditivos de comportamento, base para o desenvolvimento de programas de ensinoaprendizagem que, na perspectiva dos autores, resultariam em eficácia em relação à melhoria da qualidade de ensino.

Os autores também apontam para mais uma dimensão do acesso e uso dos dados educacionais no Brasil: as plataformas de ensino a distância. Tratar-seiam de ampla fonte de informações desagregadas no nível dos alunos que pode ser utilizada para mapear comportamentos e construir padrões para o entendimento dos processos de ensino-aprendizagem.

Os dados obtidos em ambientes de $\mathrm{EaD}$, como grandes quantidades de texto envolvendo discussões (síncronas e assíncronas) em chats, fóruns de discussão, wikis, blogs, e outras formas de interação textual entre estudante-estudante e estudante-professor, têm excelente potencial de serem utilizadas para realizar-se mineração de texto de descobrir modelos interessantes sobre os alunos (BAKER, ISOTANI, CARVALHO, 2011, p. 8)

E aqui podemos verificar uma importante mudança no entendimento da política de dados no mundo contemporâneo. Se antes, como dissemos, se tratava de um monopólio do Estado, os dados educacionais podem hoje ser obtidos por meio de diferentes plataformas, autogeridas, ampliando as possibilidades para que novos sujeitos possam disputar as políticas de dados educacionais. E, pelo o que observamos até então, são os agentes privados que têm predominado nesse campo.

\section{OS DADOS EDUCACIONAIS EM SÃO PAULO: SENTIDOS HEGEMÔNICOS}

A linha do tempo da política de dados educacionais na rede estadual paulista pode ter como ponto de partida a centralização do cadastro dos alunos, uma das medidas resultantes das Diretrizes Educacionais para o Estado de São Paulo, lançadas em 1995, na gestão de Rose Neubauer na Secretaria Estadual de Educação do governo Mário Covas (1995-1998). Tratava-se de duas diretrizes: reforma e racionalização da estrutura administrativa; mudança no padrão de gestão. Segundo Ramos (2016), estas diretrizes buscavam: 
1) a implantação de um sistema eficaz de informatização dos dados educacionais;

2) a desconcentração e descentralização de recursos e competências por meio da reorganização da estrutura da Secretaria de Educação e do estabelecimento de parcerias para prestação dos serviços educacionais (idem). No caso da mudança nos padrões de gestão, ela teria como metas: 1) a racionalização do fluxo escolar, revertendo o quadro de repetência e evasão nas escolas estaduais paulistas; 2) a instituição de mecanismos de avaliação dos resultados; 3) o aumento da autonomia administrativa, financeira e pedagógica das escolas (idem). Foi com esses contornos que se desenvolveu a gestão educacional paulista do período estudado, não obstante suas mudanças conjunturais de governos, políticas e programas educacionais (RAMOS, 2016, p. 550)

Nessa sistematização feita por Ramos (2016), fica evidente o papel que a política de dados irá desempenhar neste modelo de gestão implementado pela SEDUC-SP, a partir de 1995. A criação de um cadastro contendo amplo conjunto de informações sobre a rede possibilitaria uma gestão mais eficaz, em termos de racionalidade econômica e eficácia na produção das metas e resultados estabelecidos. Há que se destacar que em nenhuma das diretrizes, objetivos e metas estabelecidas aparece a ampliação da participação popular na gestão escolar, o que indica a forma como a NGP se consolida como mediadora da política de dados educacionais na SEDUC-SP no referido período.

Quando analisamos as primeiras medidas em relação à política de dados educacionais no início da gestão de Rose Neubauer, podemos verificar a centralidade que a lógica gerencialista assume nesse processo. Uma das primeiras medidas, por meio do Decreto 40.290 de 31 de agosto de 1995, foi a instituição do cadastramento geral dos alunos. Segundo o decreto, os principais objetivos da medida eram evitar a duplicação de matrículas e combater aquilo que denominou de "classes ociosas". Não havia menção ao debate sobre direito à educação, ancorado na ideia de ampliação do acesso, desigualdade de oportunidades, entre outros. Tratava-se, nos termos expressos no decreto, de subsidiar as ações da SEDUC-SP em vistas à maior racionalização dos usos dos recursos públicos.

Em apresentação realizada na Fundação Sistema Estadual de Análise de Dados Estatísticos (SEADE), em 2014, Rose Neubauer destacou a importância do cadastramento no processo de implementação do novo modelo de gestão da educação paulista. Segundo a ex-secretária, naquele momento foi possível elaborar um real diagnóstico da rede, de suas potencialidades e fragilidades. A partir de tais dados, obtidos com o cadastramento geral dos alunos, a SEDUCSP apresentou a Resolução SE no 15 de 13 de fevereiro de 1996, que centralizava os procedimentos de criação e extinção de classes e escolas, uma das primeiras ações na direção de implementar o projeto de reorganização escolar, posto em prática no ano de 1996. É importante destacar que os dados obtidos por meio do cadastrado não foram tema de debate público com os diferentes segmentos da 
sociedade civil. A própria celeridade do processo, verificada pelo curto período entre a publicação do decreto e da resolução, é um indicativo de que a participação popular na condução das políticas educacionais não era um dos objetivos do modelo de gestão a ser implementado.

Outra importante medida que reflete a lógica da política de dados adotada durante este período foi a criação do Sistema Estratégico de Gestão de informações através do Decreto 40.656 de 9 de fevereiro de 1996. Segundo o qual, o sistema tinha os seguintes objetivos:

I - viabilizar o uso da informação como instrumento de gestão, de maneira a, em especial:

a) atender às necessidades do processo de tomada de decisões;

b) facilitar a interação entre os membros do grupo executivo do Governo, assegurando-lhes a troca contínua e sistemática de informações;

c) contribuir para a integração das ações governamentais;

d) propiciar o controle, a avaliação e o ajustamento constante das ações governamentais;

e) permitir a otimização do uso dos recursos existentes no Estado;

II - tornar disponíveis e/ou disseminar informações que atendam a demandas dos cidadãos e de entidades da sociedade civil (SÃO PAULO, 1996d)

Nota-se, pelo decreto, que a ênfase está na ampliação da capacidade de gestão do Estado, ficando, em segundo plano, a ampliação da participação da população e da sociedade civil organizada no controle, fiscalização e participação na gestão da política pública. Esse esvaziamento da participação popular no interior da política de produção de dados pode ser verificada quando analisamos, como estava proposta no decreto, a organização do grupo gestor do sistema de informações. Composto por três unidades/entidades (Conselho do Sistema Estratégico de Informações; Unidade de Gestão Estratégica do Governo, Grupo de Coordenação do Sistema Estratégico de Informações), nenhuma delas contava com representantes da sociedade civil organizada, o que demonstra o caráter gerencialista deste sistema.

No mesmo ano, por meio da Resolução no 27 de março de 1996, o governo instituiu o Sistema de Avaliação de Rendimento Escolar do Estado de São Paulo (Saresp). Segundo a resolução, o Saresp possuía os seguintes objetivos: 
I - desenvolver um sistema de avaliação de desempenho dos alunos do ensino fundamental e médio do Estado de São Paulo, que subsidie a Secretaria da Educação nas tomadas de decisão quanto à Política Educacional do Estado; II - verificar o desempenho dos alunos nas séries do ensino fundamental e médio, bem como nos diferentes componentes curriculares, de modo a fornecer ao sistema de ensino, às equipes técnico-pedagógicas das Delegacias de Ensino e às Unidades Escolares informações que subsidiem:

a) a capacitação dos recursos humanos do magistério;

b) a reorientação da proposta pedagógica desses níveis de ensino, de modo a aprimorá-la;

c) a viabilização da articulação dos resultados da avaliação com o planejamento escolar, a capacitação e o estabelecimento de metas para o projeto de cada escola, em especial a correção do fluxo escolar. (SÃO PAULO, 1996c)

Novamente, há que se destacar o caráter gerencialista do Saresp, principalmente como instrumento capaz de produzir informações para subsidiar as decisões dos gestores públicos. Não há, na resolução, referência à participação das comunidades escolares nesse processo. A consolidação do Saresp como instrumento de controle e gerenciamento das ações dos sujeitos nas unidades escolares, em detrimento do debate ampliado sobre avaliação e seus múltiplos contextos, vai se intensificar a partir de duas novas medidas: a lei complementar 1.078, de 17 de dezembro de 2008, que institui bonificação por resultados no âmbito da SEDUC-SP e a resolução SE 74 de 6 de novembro de 2008, que cria o Índice de Desenvolvimento da Educação do Estado de São Paulo - Idesp. Publicados com diferença de pouco mais de um mês, as duas legislações são complementares e consolidam o modelo de avaliação proposto desde a criação do Saresp.

O Idesp, calculado a partir dos resultados dos estudantes no Saresp e pelo fluxo escolar, foi estabelecido também como critério para a definição dos valores das bonificações a serem pagas aos funcionários das diferentes unidades escolares que compõem a rede estadual de São Paulo. É importante destacar que, na definição das metas, em diferentes escalas, há pouca ou nenhuma indicação da participação da comunidade escolar. Segundo a lei 1.078/2008, 
Artigo $6^{\circ}$ - Os indicadores globais e seus critérios de apuração e avaliação, bem como as metas de toda a Secretaria da Educação, serão definidos mediante proposta do Secretário da Educação, por comissão intersecretarial, a ser constituída em decreto, integrada pelos Titulares das seguintes Pastas:

I - Secretaria da Casa Civil, que presidirá a comissão;

II - Secretaria da Fazenda;

III - Secretaria de Economia e Planejamento;

IV - Secretaria de Gestão Pública.

Artigo $7^{\circ}$ - Cabe ao Secretário da Educação a definição de indicadores específicos e seus critérios de apuração e avaliação, bem como as metas de cada unidade de ensino e administrativa.

$\int 1^{\circ}$ - Os indicadores, critérios e metas das unidades de ensino e administrativas deverão estar alinhados com os definidos para toda a Secretaria da Educação. (SÃO PAULO, 2008a)

Nesses termos, a dinâmica de trabalho nas unidades escolares passa a ser mediada pelas metas definidas no âmbito da SEDUC-SP, sobre as quais a comunidade escolar tem pouco poder de decisão. Assim como no caso do Ideb, tratado anteriormente neste texto, é possível verificar a consolidação de uma perspectiva de gestão dos dados educacionais na rede estadual de SEDUC-SP a partir da criação do Idesp. Novamente, há pouco ou nenhum espaço para o debate sobre avaliação em contexto, com ampliação da participação de diferentes segmentos da sociedade civil organizada e hegemonia de uma lógica gerencialista, baseada na produção de metas e resultados e na responsabilização de docentes e unidades escolares pelos possíveis fracassos.

Essa lógica de esvaziamento da sociedade civil organizada, em seus diferentes segmentos, pode ser encontrada em outras ações postas em prática pela SEDUC-SP. Destacamos duas: o processo de reorganização curricular de 2008, que instituiu o currículo do estado de São Paulo, e o projeto de reorganização escolar em 2015. Em ambos os casos, a política foi conduzida de forma autocrática pelos gestores da SEDUC-SP, sem a participação da comunidade escolar. No caso da reorganização escolar, a situação foi ainda mais grave, vide o impacto sobre a vida de docentes e discentes que seriam, compulsoriamente, transferidos de escola. Em nossa perspectiva, o modelo de política de dados e participação da SEDUCSP, expresso na reorganização de 2015, possui os mesmos fundamentos daquele, posto em prática em 1995, com a centralização do cadastro dos alunos, o que aponta para uma lógica hegemônica da política de gestão dos dados educacionais da rede estadual de São Paulo.

Essa pouca preocupação em ampliar a participação da sociedade civil na discussão pública sobre os dados e políticas educacionais será, ao nosso ver, uma dos principais responsáveis para que, somente em 2018, a rede estadual 
de educação de São Paulo lançasse uma página na internet ${ }^{15}$, disponibilizando dados educacionais, tais como: orçamento da pasta, infraestrutura das escolas, número de matrículas etc. Porém, não se trata de uma plataforma acessível, com funcionalidades clicáveis de visualização rápida das informações; ainda requer conhecimentos mínimos em manipulação de dados. Mesmo assim, está razoavelmente melhor do que antes, pois até então, a forma de se obter essas informações se dava por meio da Lei de Acesso à Informação (LAI), respondendo a um protocolo na plataforma do $\mathrm{eSIC}^{16}$ do governo estadual. Esse procedimento acabava levando alguns dias entre o pedido e a disponibilização das informações, fato que se tornava um empecilho no acompanhamento das ações governamentais. As únicas informações facilmente disponibilizadas eram os boletins, por escola, do Idesp ${ }^{17}$ e do Saresp ${ }^{18}$. Os microdados e outras formas de agregação (resultados por Diretoria de Ensino, por município etc.) só eram disponibilizadas por meio da LAI.

\section{CONSIDERAÇÕES FINAIS}

Dessa forma, essa breve retrospectiva sobre os dados educacionais na rede estadual de São Paulo nos possibilita aprofundar a discussão acerca do sentido hegemônico da política posta em prática nos últimos 24 anos. De um lado, é possível observar como tais informações possuem relevância para o poder público, com a ampliação técnica da capacidade do Estado de gerir e produzir dados. De outro, também se verifica como não houve uma efetiva utilização desses levantamentos na elaboração e avaliação das políticas públicas em educação com a participação de diferentes segmentos da sociedade civil. Ao contrário, o que a análise da documentação e das legislações pertinentes apontam é o uso vinculado à racionalidade gerencial dos dados educacionais, com vistas a implementar um modelo de gestão dos dados pautados na produção de resultados quantitativos, responsabilização e racionalização dos gastos. Em certa medida, esse uso hegemônico dos dados educacionais pode ser explicado pela centralidade que a NGP, tal como se consolida no caso aqui analisado, assume na condução das políticas educacionais no Brasil e no estado de São Paulo.

\footnotetext{
15 https://dados.educacao.sp.gov.br/

16 http://www.sic.sp.gov.br/

17 http://idesp.edunet.sp.gov.br/

18 http://saresp.fde.sp.gov.br/
} 
Nesta breve análise da política de dados, posta em prática desde 1995, é possível perceber algumas das especificidades da maneira como a NGP vem sendo adotada na rede estadual de educação de São Paulo. Como vimos, à princípio, a NGP tem como um dos seus elementos característicos a produção de dados com o intuito de promover a fiscalização e ampliar a transparência do Estado. Entretanto, tal como a NGP acontece de forma hegemônica nas políticas da SEDUC-SP, parece que a produção de dados serve muito mais ao controle e fiscalização apenas pelo próprio Estado, que exerce um novo poder invisível por meio do qual controla seus funcionários e cidadãos, favorecendo grupos diretamente vinculados a setores privados, com pouca participação da sociedade civil em geral na fiscalização do Estado.

Essa lógica de gestão dos dados tem reforçado um modelo de gestão da política pública centralizadora, como pudemos ver em episódios recentes na rede estadual de São Paulo, em especial, no processo de reorganização escolar de 2015. Sem a consulta às diferentes comunidades escolares, a proposta, baseada em dados não debatidos publicamente pela SEDUC-SP, visava os fechamentos de unidades escolares e o remanejamento de docentes e discentes. Todo o processo de condução dessa política educacional, analisada em outras pesquisas (GIROTTO, 2016; GIROTTO et al, 2017), revela o predomínio de uma política de gestão de dados assentadas nos princípios da NGP e que, como demonstra o fracasso do projeto de reorganização escolar, pouco contribuem para ampliação da participação popular e da experiência democrática na dinâmica das políticas públicas.

Assim, em nossa perspectiva, essa pouca preocupação com a ampliação do debate público e com a participação de diferentes segmentos da sociedade civil organizada nas tomadas de decisões acerca das políticas públicas educacionais pode ser uma das causas da baixa qualidade dos dados produzidos e disponibilizados pela SEDUC-SP, muito distante dos princípios dos dados e governos abertos, citadas anteriormente neste trabalho.

Nessa perspectiva, a principal tarefa dos entes públicos não é apenas disponibilizar os dados públicos, mas também incentivar a sua apropriação, reconstrução e utilização pelos cidadãos, possibilitando à sociedade maior participação e controle social da gestão pública, permitindo reduzir a assimetria de informações entre o governo e a sociedade civil. No entanto, o que se verifica é uma utilização esporádica e impulsionada por circunstâncias particulares e pela combinação de uso aleatório dos dados por jornalistas, organizações não governamentais e público em geral (KLEIN; KLEIN \& LUCIANO, 2019, p. 12 13); e um dos motivos para essa reduzida participação de diferentes segmentos da sociedade civil organizada nas tomadas de decisões acerca das políticas públicas 
educacionais pode estar relacionada à falta de qualidade dos dados, uma vez que "a qualidade da informação determina a intenção de uso de dados do governo pelos cidadãos" (ibidem). Não se trata, porém, em nossa perspectiva, de um equívoco da gestão, mas de uma lógica de gestão que tem no controle centralizado dos dados e no esvaziamento da gestão democrática um pilar estratégico de condução das ações do governo.

Como dissemos, trata-se, ainda, de resultados parciais de pesquisa. É fundamental discutir, posteriormente, com mais detalhes, como se articulam os agentes públicos e privados no processo de gestão dos dados educacionais na SEDUC-SP, analisando se esta seria uma das estratégias no processo de consolidação de formatos e dinâmicas de privatização da educação pública. As análises construídas até aqui nos permitem verificar que o controle da gestão de dados é uma das condições de ampliação do poder na condução das políticas públicas pelos grupos privados na SEDUC-SP. Identificar e discutir como se consolida, em detalhes, este processo é um dos objetivos que esperamos alcançar ao final desta pesquisa.

\section{REFERÊNCIAS}

AZANHA, J. M. Uma ideia de pesquisa educacional. São Paulo: EDUSP, 2014.

BOBBIO, N. O futuro da democracia. $2^{a}$ edição. São Paulo: Paz e Terra, 1986.

BAKER, R. S. J. de; ISOTANI, S., CARVALHO, A. M. J. Baker de. Mineração de dados educacionais: oportunidades para o Brasil. Revista Brasileira de informática na educação, vol. 19, n. 2, 2011.

BROOKE, N.; CUNHA, M. A. A. A avaliação externa como instrumento da gestão educacional nos estados. In: Estudos e Pesquisas Educacionais Volume 2. São Paulo: Fundação Victor Civita, 2011.

CALDERANO, M. da A. et al. O que o IDEB não conta. Juiz de Fora: EDUJF, 2013.

FLETCHER, P. R. Propósitos da Avaliação Educacional: uma análise das alternativas. Estudos em Avaliação Educacional. n. 11, 1995. 
FREITAS, L. C. de. Eliminação Adiada: o ocaso das classes populares no interior da escola e a ocultação da (má) qualidade de ensino. Educação \& Sociedade. vol. 28, n. 100, outubro, 2007.

GIROTTO, E. A dimensão espacial da escola pública: leituras sobre a reorganização da rede estadual de São Paulo. Educação \& Sociedade, Campinas, 37 (137), 2016.

GIROTTO, E.; PASSOS, F.; CAMPOS, L.; OLIVEIRA, J. A geografia da reorganização escolar: uma análise espacial a partir da cidade de São Paulo. Educação temática digital, v. 19, 2017.

ISSA, M. K. Dados abertos Governamentais: Implicações e possibilidade em políticas públicas. 2013. Dissertação (Mestrado em Ciências Sociais) - Pontifícia Universidade Católica de São Paulo, São Paulo.

KLEIN, R. H.; KLEIN, D. C. B.; LUCIANO, E. M. Ampliação da transparência de dados abertos governamentais: a percepção dos observatórios sociais brasileiros. Contextus: Revista Contemporânea de economia e gestão, v. 17, n. 1, p. 8 - 36, 2019. Disponível em: < http://periodicos.ufc.br/contextus/article/ view/32834/pdf_1>. Acesso em: 15 jul. 2020.

LIMA, A. A. A.; SOUSA, F. P. Censo Escolar da Educação Básica: Uma referência para elaboração de políticas públicas e transferência de recursos para Educação Pública. Revista Com Censo: Estudos Educacionais do Distrito Federal, [S.1.], v. 1, n. 1, p. 94-102, dez. 2014. ISSN 2359-2494. Disponível em: <http:// periodicos.se.df.gov.br/index .php/comcenso/article/view/25>. Acesso em: 23 jan. 2020.

NÚÑEZ, C. P.; KOSLINSK, M. C.; FERNÁNDEZ, S. J. Políticas de incentivo ao uso de dados educacionais: experiências no contexto internacional e brasileiro. Jornal de Políticas Educacionais. V. 13, n. 17. Maio de 2019. Disponível em: <http://10.5380/jpe.v13i0.64894>. Acesso em: 10 jul. 2020.

OPENGOVDATA. Eight principles of open government data. Dezembro de 2007. Disponível em: <www.opengovdata.org/home/8principles>. Acesso em: 12 jul. 2020. 
POSSAMAI, A. J.; SOUZA, V. G. de. Transparência e Dados Abertos Governamentais: Possibilidades e Desafios a Partir da Lei De Acesso À Informação. Administração Pública e Gestão Social, vol. 12, n. 2, 2020. Disponível em: https://periodicos.ufv.br/apgs/article/view/5872/5460. Acesso em: 15 jul. 2020.

RAMOS, G. P. Racionalidade e gerencialismo na política educacional paulista de 1995 a 2014: muito além das conjunturas. Ensaio: avaliação de políticas públicas educacionais. Rio de Janeiro, v. 24, n. 92, jul.-set., 2016.

SANTOS. O. A. R. Minha Escola Transparente: Uma análise comparativa do uso de dados governamentais abertos na educação básica no Brasil e Inglaterra. Dissertação (Mestrado) apresentada na Escola Brasileira de Administração Pública e de Empresas, Centro de Formação Acadêmica e Pesquisa. FGV. 90 p. Rio de Janeiro, 2014.

SÃO PAULO. Resolução $\mathrm{SE} \mathbf{n}^{\mathbf{0}}$ 15. Dispõe sobre procedimentos quanto à autorização de transformação de escolas, instalação, criação e extinção de classes. São Paulo: SEE-SP, 1996 a.

SÃO PAULO. Resolução SE $\mathbf{n}^{\circ}$ 17. Constitui o Grupo Setorial de Informações Estratégicas e dá providências. São Paulo: SEE-SP, 1996b.

SÃO PAULO. Resolução $\mathrm{SE} \mathbf{n}^{\circ}$ 27. Dispõe sobre o Sistema de Avaliação de Rendimento Escolar do Estado de São Paulo. São Paulo: SEE-SP, 1996c.

SÃO PAULO. Decreto 40.656. São Paulo: SEE-SP, 1996d.

SÃO PAULO. Lei complementar $\mathbf{n}^{\mathbf{0}}$ 1.078. São Paulo: SEE-SP, 2008a.

SÃO PAULO. Resolução SE n $^{0}$ 74. São Paulo: SEE-SP, 2008b.

SOUZA, C. Políticas públicas: uma revisão da literatura. Sociologia. Porto Alegre, ano 8, no 16, julho de 2006.

VERGER. A; NORMAND. R. Nueva Gestión Pública, y Educación: Elementos teóricos y conceptuales para el estudio de un modelo de reforma educativa global. Educação \& Sociedade, v. 36, n 132, p. 599-622. Campinas, 2015. 


\section{Eduardo Donizeti Girotto}

Mestre e Doutor em Geografia Humana. Professor do Departamento de Geografia da Universidade de São Paulo. E-mail: egirotto@usp.br

\section{João Victor Pavesi de Oliveira}

Mestrando em Geografia Humana, Universidade de São Paulo. E-mail: joao. pavesi@gmail.com

\section{Isabel Furlan Jorge}

Mestranda em Sociologia, Universidade de São Paulo. E-mail: isabel.fj@hotmail. com

Recebido em 27/01/2020

Aprovado em 20/07/2020 